Marina MATIĆ BOŠKOVIĆ, PhD* Institute of Criminological and Sociological Research, Research Fellow
Review Scientific Article

Received: 28 October 2020

Accepted: 25 November 2020

UDK: $311.3: 347.9$

005.6:347.9

https://doi.org/10.47152/rkkp.58.3.6

\title{
COURT STATISTICS - A TOOL FOR MANAGEMENT AND STRATEGIC PLANNING
}

Court statistics developed over the time from bureaucratic data collection to monitoring and evaluation of court performances and judicial reforms. In the Europe, the Council of Europe CEPEJ contributed to the promotion of court statistics as a tool for management over judiciary and evaluation of judicial performances.

Modern use of statistical reporting requires setting of performance indicators, which tracking will enable monitoring of court performance and inform decision making on further actions. Some of performance indicators are recommended by the CEPEJ and are widely accepted, like clearance rate and disposition time. However, court statistics could include information beyond court cases, like financial data per court and human resource data, which could inform interventions in the area of human resource management and financial resource management, i.e. equalization of workload among courts and judges, as well as calculation of cost per case.

The use of information and communication technologies (ICT) in the courts and court statistics contributed significantly to improvement of administration of justice, through development of automatized case management systems, automatic export of relevant reports on court performance based on predefined indicators. However, few preconditions are required for successful deployment of the ICT in judiciary.

e-mail: maticmarina77@yahoo.com 
Countries were putting efforts to strengthen court statistics and some good practices were developed over time. Slovenia dashboard for improvement of disposition time and Serbian court maps for tracking backlog reduction are good examples that could be used replicated in countries with similar challenges and goals.

Key words: court statistics, case management, ICT, decision making, administration of justice

\section{Introduction}

The institutional framework within which courts historically operated placed little emphasis on management and administrations, however over the last few decades a variety of management principles and practices have been introduced into the court systems. ${ }^{1}$

Many countries across the world have undertaken judicial reforms as part of broader public administration reforms. Despite the growing demand there is not sufficient quantitative data to make assessment of judicial reforms (Dakolias, 1999: 2). Reasons for that are twofold: national judiciaries were not historically concerned with performance data and comparative law scholars prioritize qualitative to quantitative comparisons.

Change in the approach influenced on introduction of a systematic approach to improve organizational performance by using statistics and statistical thinking in justice reforms and is the base for many success stories. Private entities and modern public sector agencies alike use data and data analysis for decision-making, to link different segments of organizational performance, and predict future performance and plan for desired outcomes (Dransfield, Fisher, Vogel, 1999: 122).

One of the key preconditions for successful reforms in the justice sector and management of judiciary is existence of the robust evidence and analysis underpinning the design of reforms. Stakeholders are now interested if policies, programs and projects led to desired outcome and results (Kusek, Rist, 2004: 3). It is widely accepted by all relevant stakeholders that for building results-based monitoring and evaluation systems and making necessary decisions in the process of justice reforming there should be necessary statistical data which would be strong ground for doing reforms in right directions (Matić Bošković, 2017: 80). Statistical data should be valid, verifiable, transparent and widely available to the government and interested stakeholders.

1 See: UNODC (2011) Resource Guide on Strengthening Judicial Integrity and Capacity. Vienna: UNODC, pp. 39-59. 
Judicial management is becoming increasingly important. How advanced countries are in using statistics to inform and steer reforms and change management efforts vary. Technological innovation and the use of big data systems allow all sorts of analyses from resource allocation and investment planning to tracking of impact of legislative changes. The use of the information and communication technologies (ICT) is considered as one of the key elements for improvement of administration of justice that opened opportunities for efficient management (Velicogna, 2007: 129). Although potential benefits of the ICT use are not disputable, the adoption of new technologies in the justice sector in many countries has been slow, inefficient, expensive and poorly designed (Cordella, Contini, 2020: xii). Introduction of ICT in the justice sector has lagged behind other sectors due to the organization of judiciaries, resistance to the introduction of new processes, politically complex interaction between different actors, government and judiciary.

Judiciaries around the globe are held more and more accountable for state funds devoted to their functioning and quality of service delivery. However, without a clear data analysis strategy a lot of hard work of individuals can be either lost or not valued appropriately. The efficiency and quality of different judicial systems is more and more debated and compared through different organizations and models.

The Council of Europe's (CoE) European Commission for the Efficiency of Justice (CEPEJ) has identified three main uses of data according to its "Monitoring and Evaluation of Court System: A Comparative Study". One: jurisdictions where data is collected (and stored) but no analysis is undertaken, and no actions taken based on analysis insights. Two: countries, like France, the Netherlands and Italy, are using - in differing degrees - data collected to hold courts to account for spending or to allocate resources and to make the judiciary more transparent. Three: countries, like Slovenia, use data to track progress in the organization of judiciary and to adjust policies and reform efforts accordingly.

\section{From Reporting to Managing}

The main change in using judicial statistics is from statistical reporting, which is characteristic of bureaucratic data collection, to strategic management (Hodzic, 2017: 7). Bureaucratic data collection takes place outside of monitoring and evaluation purposes. Vast amount of human and financial resources is spent on manual collection of data for purposes of usually late reporting, with no evidence of use of data for policy decision making. Examples for courts include the registration of cases in paper and electronic registers, data collected in case tracking systems. These basic forms of data collection are ingrained in traditional court 
procedures and regulations. Such data is usually collected according to standards and procedures individual to the court or according to data entry methodologies which are also individual to the court. Such data can be adapted for internal monitoring and evaluation purposes at court level.

Use of statistical data for monitoring and evaluation purposes requires benchmarking of data against set standards at the global level. Statistical system based on the available court data should be established to enable stakeholders to monitor the performance of the justice sector and courts, monitor the impact of legal and judicial reform aimed at improving performance, enable evidence-based decision making, allocate financial and human resources among the court fairly. Use of statistical data are especially relevant in the area of criminal procedure due to significant reform changes across Europe with the aim to improve efficiency of criminal proceedings (Simović, Šikman, 2018: 38).

To make the move from tracking cases towards managing court performance requires identification and setting of performance indicators (Hammergren, 2014: 93). Performance indicators can be used for snapshot comparisons (crosssectional) or tracked over time to examine trends and the effects of changes (time series). Comparisons should be made with care and treated with caution, however. Statistical data need evaluation to add meaning as they do not take account of the variety or complexity of individual cases, the legal instruments available (including simplified procedures) or wider socio-economic factors such as increases in criminality or a tendency to litigate, the introduction of new laws, etc. Hence, the value-added of performance indicators stems from their interpretation and any comparison should always be made with care and caution.

A judiciary's ability to identify such performance indicators and set realistic, yet ambitious performance targets is linked to its level of court automation as well as staff skills and capacity to analyze data and statistics from various sources in real-time. In some countries, for example Slovenia, Romania, and the Netherlands, the judicial branch has made significant advances in introducing and interlinking case management, human resource and financial management systems, often in collaboration with the executive branch.

Overall, information and communication technologies (ICT) have revolutionized data collection and data use. Instead of the old paper-based system, completed by hand and posted to a central location for manual entry into a database, ICT allows each court to submit information directly and automatically subject to statistical quality control. ICT can facilitate dynamic and flexible data processing, mining and manipulation to deliver analytical reports on demand. To get most out of ICT systems, strong analytical skills and clearly defined staff roles and responsibilities for court statistics are required. 
The demand for business intelligence in the justice sector builds, major case management software vendors are replacing standard static reports with interactive, easy-to-use performance dashboards integrated with their automated case management systems (Keilitz, 2010: 76). Use of business intelligence in the statistics turns existing data into actionable knowledge by for example calculating position of individual courts in one of the following categories: green color - good performance and use of resources; yellow color - good performance due to surplus resources; beige color - low performance probably due to insufficient resources; red color - low performance despite sufficient resources. This model and use of business intelligence should guide policy-making processes and managerial decision at the courts level.

- There is consensus and empirical evidence in the affirmation that the application of the ICT in courts carries with it a multitude of benefits, among which it should be mentioned (Cerrillo, Fabra, 2009: xiii):A more efficient judicial system in the way it increases productivity and diminishes costs of transaction from the system which is highly information intensive;

- A more effective judicial system by reducing the duration of procedures;

- Increasing the citizens' level of access to judiciary by providing the best information available and a better understanding not only the way courts work but also of the legal instruments in their reach to ensure recognition of their rights;

- Improved transparency of the way the judiciary works in the technologies facilities an improved control of cases and allow a better qualitative evaluation of outputs;

- Increase in the confidence of citizens and business in the judicial system;

- Greater legitimacy of judicial power.

\subsection{Use of court statistics in daily operations}

Regardless of its enhanced scope any e-justice system will need to rely on quality statistics to monitor and manage court performance. To enable smooth application of statistical data in decision making process the statistical data should be generated automatically and summarized in a user-friendly format. Potential users of statistical reports depend on organization of the justice system in the specific country and could range from the judicial councils, courts, the Ministry of Justice (MoJ), the Government to media, court users and the general public. In addition, public information on court cases is also available online.

Usually on line system have information on court hearing schedule, enables search for cases similar in specific parameters, and search for legal cases by case 
type, case number, court name, judge name, plaintiff name, defendant name, filling date, matter of litigation, date of verdict, law article, etc. as well as for cases with similar features, other applications, such as "online applications" are frequently the next step in the system development.

Court performance measurement is the discipline and the process of monitoring, analyzing and using organizational performance data on regular and continues basis for the purpose of improvements in organizational efficiency, effectives, in transparency and accountability, and in public trust and confidences in the courts and the justice system (Keilitz et al, 2018: 6).

In addition to the focus on court performance, jurisdictions have begun to use statistical data and performance indicators as objective tools to evaluate the work of judges. With the help of statistical information, bottlenecks in performance and areas for improvement can be identified, and feed into promotions and disciplinary actions against judges. Reliable and timely data will facilitate improved outcomes.

\subsubsection{Use of statistical data beyond cases}

Reliable and uniform registration of cases, proper case differentiation, and periodic data collection are also a precondition for an effective budgeting approach. Supporting software tools, staff capacity and authority over statistics are preconditions for effective budgeting and expenditure control. Judiciaries with well-developed formulas and means of data collection for determining output levels, such as the Netherlands and the US State of New Jersey, are better positioned to plan their operations, allocate funding appropriately and timely and request additional resources based on gaps identified or mitigate against any efforts to reduce their funding. Other jurisdictions, such as Slovenia, may not use a formula-basis for court budgeting and instead consider performance in building the budget and making allocations.

Frequently, increased transparency in judicial operations has a positive impact on judicial accountability as links between judicial bodies, other branches of government and society overall are strengthened, and reform efforts can be assessed with the help of feedback loops. In acknowledgement of this potential, public accountability and transparency, in the form of publishing of reports and performance statistics are included in the judicial strategic documents of many countries. It is also recognized as priority in the EU accession process and as such included as an impact indicator of improved perception of data transparency in the relation to the efficiency of judiciary and in the related activities. ${ }^{2}$

2 Action plan for Chapter 23 in Serbia and Montenegro. 


\subsection{Statistical Data}

Each country decides on type of data that will be collected, depending on the organization of judiciary, competences for the case management, but also human resource and financial resource management. The CEPEJ Guidelines on Judicial Statistic ${ }^{3}$ recommend collecting broader performance data. In specific, the following data categories should be collected to facilitate performance management of courts:

- general information concerning the court, i.e. budget implemented and available human resources in full-time equivalents (judges, judicial assistance and non-judicial staff);

- workflow information per case category

- number of cases pending as of 1 January of the year;

- number of cases registered during the year;

- number of cases resolved during the year;

- number of cases pending as of 31 December of the year;

- number of appealed decisions;

- number of quashed or modified decisions;

- age of pending cases.

Not all of this broader performance data is available in the national statistics, so countries are not in the position to develop enough indicators to measure all relevant aspects of court performance. For example, many countries missing data on the age of pending cases or the cost per case. The first would help to mitigate (an increase in) backlog, while the second ensures best use of scarce resources and proper budget planning. The minimum data set that should be readily available for meaning court performance management is outlined below:

- General information concerning the court:

- Judicial assistants per judge ratio

- Non-judicial staff per judge ratio

- Total number of staff per judge ratio

- Incoming, resolved, pending per judge ratio

- Incoming, resolved, pending per staff ratio

- Cost per case

3 CEPEJ (2008) CEPEJ Guidelines on Judicial Statistics, available at: https://rm.coe.int/1680747678, accessed on 26.10.2020. 
- Workflow information per case category:

- Clearance rate

- Disposition time in days

- Ration regarding the structure of incoming, resolved, pending cases

- Information on appeals per case category - appeals ration and quashed or modified decisions ratio

- Age of pending cases, i.e. aging list

Expanding the data collection and analysis with performance data would put court administrations into the position to eventually calculate and set a broad set of performance targets and steering desired change on the way judicial services are delivered today (Buscaglia, Dakolias, 1999: 7).

The introduction of indicative timeframes could help to increase timeliness of court proceedings. Lengthy judicial proceedings are frequently an issue in member states of the Council of Europe and may infringe Article 6 of the European Convention of Human Rights requesting courts to deal with cases within a reasonable time. Timeframes help to measure to what extent each court and the justice system pursue the required timeliness of case processing. The current situation should be diagnosed, and possible bottlenecks be identified in order to set appropriate timeframes, which would be informed by the case law of the European Court of Human Rights. The identified timeframes could then be piloted, monitored and evaluated, discussed and adjusted as per the pilot's outputs before scaling-up. The CEPEJ 2016 Implementation Guide on Timeframes ${ }^{4}$ could serve as a guidance for judicial stakeholders in this process. The existence of a robust case management system and accurate statistical data are preconditions for introducing timeframes.

Improvement of court statistics would also impact cooperation with CEPEJ, as the Council of Europe's responsible body for the performance of justice sector entities. CEPEJ requests its members to regularly report on performance via a standardized questionnaire. For the judiciary and prosecution this means every two years following a specific procedure.

4 CEPEJ (2016) Towards European Timeframes for Judicial Proceedings Implementation Guide, available at: https://rm.coe.int/16807481f2, accessed on 26.10.2020. See: "Timeframes should be set not only for the three major areas (civil, criminal, administrative), but they should progressively be set for the different Case categories dealt with by the court. Timeframes should be tailored to each case category (e.g. family matters, bankruptcy, labor etc.), and local circumstances, depending on procedural issues, resource available, and legal environment". 


\subsection{Use of ICT in Courts}

Introduction of ICT aimed at increasing judicial efficiency and reducing the cost of administration and management of the judiciary are common all over the world. ICT could also help courts to achieve values of legality, transparency, economy and access to justice. ICT could be used for introduction of automated case management system to support work and daily operations of courts, as efilling and electronic exchange of procedural documents and interoperability platforms that are mostly relevant for criminal justice.

Statistics requires use of the ICT, however it requires sufficient financing from the state budget to ensure modern hardware, internet connections across the country to include all courts and server capabilities. ICT literacy generally should be high across the judiciary, and basic computer training has to be provided for judges, prosecutors and court staff to ensure proper use of the software. In addition, courts should have ICT support staff, who are well trained.

In relation to the ICT use in court statistics many countries relay on donor support, which influence on update and maintenance of the system. Many system include the automated case management system for case management and case allocation; document circulation; budgeting, and human resource. These automated systems usually include opportunity to search and analyze by case type, by court and by individual judge. The poor quality of the data entered in case management system (CMS) is another common problem, which is addressed through CMS functionalities for standardization data entry.

The automated case management systems usual have options to export statistical reports. Frequently data filters enable the options for using available data, while convenient and process-facilitating functionalities such as a calendar with automatic and customized notifications removes the burden from court staff.

Many systems lack interoperability and does not facilitate electronic data exchange with other institutions. Interoperability of systems and readily available data help to speed up data exchange between units and entities and hence to reduce average time for case processing and costs of mail services. Ideally, data is electronically exchanged between justice sector institutions, such as courts, prosecution, enforcement and notaries, as well as registers and records at the Ministry of Justice and Minister of Interior and other relevant institutions, as necessary.

\subsection{Publication of Statistics}

Transparency of judicial system generates an increased flow of information from the judiciary to society, enabling the public to learn about its performance 
(Herrero, Lopez, 2010: 9). Even when statistical information are publicly available, it should be published in a user-friendly format and empower the (lay) audience to understand courts performance. Challenges to understand are likely to negatively impact trust among citizens and businesses into the court system on the one hand. On the other hand, organizing and presenting the collected data in forms tailored to various target audiences, such as judges, court staff, partners of the judicial system, businesses and the general public would go a long way in increasing transparency around court performance and increasing access to information.

Ideally these efforts are built into an overall communication plan to inform and educate, in particular business and the general public about courts and effectively share key messages, including about reform initiatives, goals and achievements. Elements of particular interest to court users, such as 'how long will it take the court to consider my case (i.e. average length comparable cases are under examination)?', 'why does it take the court so long to summon me?', 'if the decision is not in my favor, what are my chances to win an appeal?', should also be included and highlighted given their frequency and relevance. New technologies and social media such as Facebook, YouTube, and Twitter, are transforming the way (potential) court users seek out information and understand the world. These communication tools provide opportunities for courts to promote openness and accountability, and can encourage conversation between the judiciary, journalists, citizens and businesses. Most importantly, they present opportunities for courts to listen to public concerns and enable a feedback loop.

\section{Good practices - use of statistics for management purposes}

Most of the EU Member States are using statistical data for management purposes, by identifying efficiency indicators to assess the proper functioning of their courts. Some of the efficiency indicators are the following: number of incoming cases; length of proceedings; number of closed cases; pending cases and backlogs; and productivity of judges and court staff. The efficiency of the court system can be assessed by calculating two composite metrics from the number of incoming, resolved and unresolved cases, namely clearance rates and disposition times. Practices presented from Slovenia and Serbia are useful for any judiciary as examples of use of statistical data to plan and improve efficiency, decrease backlog and improve exchange of information. 


\subsection{Slovenia - Judicial Data Warehouse and Performance Dashboard}

The court system in Slovenia is collecting and capturing performance information in its data warehouse, to improve planning, decision-making at all levels, and human resources management. Apart from the instantaneous access to the latest data, the visualization of key performance indicators through the Judicial Data Warehouse and Performance Dashboard project increased transparency. ${ }^{5}$ By monitoring the efficiency of court operations, the system has helped to raise productivity, and helped to drive down the number of pending cases and disposition times.

Improvement of statistical reporting in Slovenia was part of the package of reforms focused on backlog reduction which should enable monitoring of the courts' work based on uniform criteria. The Court's Act prescribes a number of reports and documents, which are to be prepared by court presidents and directors as part of their court management duties and responsibilities for the performance of their courts.

Before 2008, court registers in Slovenia were managed for individual types of procedures, and not on the level of whole court, and were filled manually every three months, with only basic data - new, solved and unresolved cases, and the start and end date of the procedure. Data was submitted in the static form of statistical spreadsheets. The work of the courts was measured, but it did not determine causes, reasons for the situation, or improve operations.

To generate better quality and more reliable information, the Supreme Court of Slovenia developed and implemented a new approach to court management by combining business-intelligence technology with managerial know-how. A Data Warehouse project ${ }^{6}$ and reporting system was initiated to allow information to be collected electronically, centrally and automatically, to permit enquires against a range of indicators such as disposition time, clearance rate, age of pending caseload and to enable reports to be produced on demand and facts to be presented in a user-friendly format.

5 The project was a finalist in the CEPEJ and European Commission "Crystal Scales of Justice Competition" in 2012.

6 Data warehousing is a process which turns raw data into potentially valuable information assets by: applying standards and consistency to the data; integrating the data; enforcing data consistency over time to provide meaningful history; organizing the data into subject areas crossing business functional lines acting as a stable and reliable source; and providing easy accessibility. 
The Data Warehouse project improved decision-making and productivity by shortening the decision-making time and eliminating backlogs. ${ }^{7}$ The system enabled gaining a better overview of the work of courts and allowing benchmarking between courts, enabling a more efficient resolution of old cases, allowing effective planning and equalization of human resources in different courts, rationalizing the costs and removing burdening from judges of preparing statistical analysis.

Additional tool developed in Slovenia, the President's Performance Dashboard was created to enable presidents to manage work of the court. The Dashboard is user-friendly and graphically effective way to present court performance.

One of the key factors for success was communication and cooperation between the top leadership regarding demands and expectations and the technical team regarding possible opportunities and challenges. The Supreme Court of Slovenia was champion of change and was leading whole process of development, introduction and monitoring of Data Warehouse project. In addition, the regular trainings were provided for court managers to ensure unified application in the practice. The Supreme Court was using information collected through statistics and data from Wearhouse to develop strategic documents - Slovene Judiciary in Europe 2020 - Strategy for the Sustainable Independent Judicial Branch of Power.

The Data Wearhouse enabled Supreme Court to achieve implementation of priorities set in 2013. The Slovenian judiciary achieved to clear cases within prescribed timeframes; solve the oldest unresolved cases; reduce the burden on judges and leveling human resources. For the human resource management purposes, the Supreme Court was using information tool to assess the burden and productivity of judges and other personnel within different courts and assign resources to avoid imbalances in relation to caseload.

\subsection{Serbia - Centralized Statistical Database}

The centralized statistical database represents business intelligence tool for statistics and reporting regarding work of courts of general jurisdiction. It collects data from decentralized databases of basic and higher courts (AVP system). From October 2017, it is in operation, and enables use of data concerning courts, research and analytics for most of the basic courts. Primary users are statistics

7 More information are available at: $\mathrm{https}$ ://rm.coe.int/judicial-data-warehouse-and-performancedashboards-supreme-court-of-sl/168078b0cb, accessed on 30.10.2020. 
analysts in MoJ, Supreme Court of Cassation, and High Judicial Council. Furthermore, it is the instrument for control of compulsory reporting by courts.

The Centralized statistical database is a pioneering effort to enable 'one click' centralized performance statistics for all basic and higher courts in the Republic of Serbia. The aim of the initial project was to solve a long-standing problem with collection of court statistical/performance reports from the AVP case management system, which is distributed by its nature (i.e. every court hosts a separate server which records its case data). In addition, the initial version of the centralized statistics served as a "proof of concept", that it is possible to implement such a solution for collection, aggregation, and processing of court case data.

Before the implementation of the centralized statistical system, the only way to obtain a statistic for entire system of basic and/or higher courts, was to request individual reports in Excel format, and then manually combine/aggregate these reports into cumulative report. This process was extremely error-prone and time consuming, so basically performance reporting was limited to 6 months and High Judicial Council, Supreme Court of Cassation and Ministry of Justice to monitor performance of the courts and observer red-flags in some of them (i.e. sudden inflow of new cases, or dramatic decrease in disposition ratio).

The implementation of centralized statistics was conducted in close cooperation between Ministry of Justice, High Judicial Council and the Supreme Court of Cassation. The concept of the system relied on nightly replication of the AVP data from individual courts to the centralized server hosted in the Supreme Court of Cassation, aggregating the data into data warehouse and then crunching and processing these aggregate information and presenting them in the form of tabular reports and various data visualisations (bar charts, pie charts etc.). The system offers predefined reports by number-of-cases criteria of at court registers, and on other hand, this platform contains modern tools for creating customized reports by every possible criteria and filters, enriched with high variability of graphic data visualization.

The system has been further developed by the Ministry of Justice and is currently in production use, with all basic and higher courts being provided with user accounts for access to the centralized statistical database.

The backlog reduction related data from the centralized statistical tool is being used for update of the Interactive Court Map. The map is an online publicly accessible tool for monitoring of the individual courts backlog reduction progress on monthly basis. Based on data on backlog reduction the Supreme Court of Cassation can work with individual court on development of their individual backlog reduction plan or its revision to address challenges identified through statistics. 


\section{Conclusions}

Although performance of judiciary historical was not a concern, last few decades approach was changed both in the USA and Europe. Council of Europe CEPEJ introduced comparative, multi-country approach of measuring judicial efficiency and influenced on Council of Europe countries to improve national statistics and data collection processes to be enable collection of needed data for CEPEJ reporting. CEPEJ working groups influenced on defining different performance indicators that could support monitoring of progress in efficiency, but also in deployed resources (financial, human and ICT resources).

Examples form Slovenia and Serbia showed how strengthening of statistics and introduction of business intelligence tool improves monitoring and evaluation of justice reform efforts. Both countries set improvement of efficiency as priority and collection of specific data as well as introduction of monitoring mechanism though dashboards in Slovenia and court map in Serbia enabled improvement of disposition time in Slovenia, and in Serbia reduction of backlog as one of the main obstacles for the efficiency of Serbian judiciary.

Court statistics is most often use for monitoring and improvement of judicial efficiency through improvement of disposition time, setting timeframes, collecting aging list, reducing number of old cases, tracking of cases from initial act to final decision, etc.

However, as it was discussed above, the statistics is valuable tool for equalization of workload across the judiciary, courts of same jurisdiction and same level and judges within the one court and across courts network. Equalization of workload ensures optimal use of available resources and employment satisfaction. In using of statistics to ensure equalization of workload there should be taken into account number of cases, but also complexity of cases.

Improvement of court statistics could also support financial management in judiciary, through evaluation of used financial resources, better planning and execution of budget. The robust statistical system can enable calculation of cost per case which could indicate differences in costs across the system and identify which specific cost contributed to inequalities.

To enable success in strengthening of court statistics there is a need to have clear vision of the goals and willingness to improve statistics, both quality and accuracy of data and scope of data that are collected. In addition, there should be readiness among key stakeholders to use statistics as monitoring and evaluation tool that will inform decision making. In addition, there is a need to have leadership of the process as well as strong commitment of all judicial authorities (i.e. Supreme Court, Judicial Council, courts and court presidents) as well as other 
judicial stakeholders whose involvement is critical, depending on the organization of national system (i.e. Ministry of Justice).

Strengthening of court statistics requires investment in resources, both human resources and ICT. It is clear that development of the automated case management system, as well as introduction of business intelligence enable better utilization of courts statistics. Precondition for introduction of ICT in court statistics is allocation of sufficient budget resources for development of software and purchase of adequate hardware, as well as existence of stable internet connections in all courts. When it comes to human resources, employment of ICT experts in the courts and judiciary is necessary to ensure internal know-how and maintenance of the system, but also it is important to increase ICT literacy of court's staff and judges.

\section{Literature}

- Buscaglia, E., Dakolias, M. (1999) Comparative International Study of Court Performance Indicators: A Descriptive and Analytical Account. Washington DC: Legal and Judicial Reform Unit, Legal Department, The World Bank, available at: http://documents1.worldbank.org/curated/en/373641468769467659/pdf/ multi-page.pdf

- Cerrillo, A.M., Fabra, P.A. (eds.) (2009) E-Justice: Using information communication technologies in the court system. New York: Information Science Reference.

- Cordella, A., Contini, F. (2020) Digital Technologies for Better Justice - A Toolkit for Action. Inter-American Development Bank, doi: http://dx.doi. org/10.18235/0002297

- Dakolias, M. (1999) Court performance around the World. World Bank Technical Paper, (430), available at: http://documents1.worldbank.org/curated/ en/639261468758377643/pdf/multi-page.pdf

- Dransfield, S.B., Fisher N.I., Vogel, N.J. (1999) Using Statistics and Statistical Thinking to Improve Organisational Performance. International Statistical Review, 67(2), pp. 99-150.

- Hammergren, L.A. (2014) Justice Reform and Development: Rethinking Donor Assistance to Developing and Transitional Countries. New York: Routledge.

- Herrero, A., Lopez, G. (2010) Access to Information and Transparency in the Judiciary. Governance Working Paper Series. World Bank Institute.

- Hodzic, A. (2017) Courts Performance Management, Support to Justice Sector Reforms in Ukraine, EU, available at: https://www.pravojustice.eu/storage/ app/uploads/public/5ae/f8e/8d5/5aef8e8d595b6456536760.pdf 
- Keilitz, I. (2010) Smart Courts: Performance Dashboards and Business Intelligence. Future Trends in State Courts 2010, pp. 73-78, available at: https:// cdm16501.contentdm.oclc.org/digital/collection/ctadmin/id/1613

- Keilitz, I., Glanfield, L., Hall, D., Richardson, L. (2018) Global Measures of Court Performance. Melbourne: International Consortium for Court Excellence.

- Kusek, J.Z., Rist, R.C. (2004) Ten steps to a Results-Based Monitoring and Evaluation System: A Handbook for Development Practitioners. Washington DC: World Bank.

- Matić Bošković, M. (2017) Management of Court Performance as part of Judicial Accountability. Strani pravni život, 61(2), pp. 77-92.

- Simović, M., Šikman, M. (2018) Efficiency of Criminal Proceedings - Between Expectations and Reality. Journal of Criminology and Criminal Law, 56(3), pp. 23-43.

- Velicogna, M. (2007) Justice Systems and ICT - What can be learned from Europe?. Utrecht Law Review, 3(1), pp. 129-147, doi: https://doi.org/10.18352/ $\underline{\text { ulr.41 }}$

Other Sources:

- CEPEJ (2007) Monitoring and Evaluation of Court System: A Comparative Study.

- CEPEJ (2008) CEPEJ Guidelines on Judicial Statistics, available at: https:// rm.coe.int/1680747678, accessed on 26.10.2020.

- CEPEJ (2016) Towards European Timeframes for Judicial Proceedings Implementation Guide, available at: https://rm.coe.int/16807481f2, accessed on 26.10.2020.

- UNODC (2011) Resource Guide on Strengthening Judicial Integrity and Capacity. Vienna: UNODC.

Online sources:

- https://rm.coe.int/judicial-data-warehouse-and-performance-dashboards-supreme-court-of-sl/168078b0cb, accessed on 30.10.2020. 